\title{
Converting traditional materials labs to project-based learning experiences: Aiding students' development of higher-order cognitive skills
}

\author{
Linda Vanasupa, Katherine C. Chen, Jonathan Stolk*, Richard Savage, Trevor Harding, Blair \\ London, and William Hughes
}

\begin{abstract}
Materials Engineering Department, California Polytechnic State University
*Engineering, Franklin W. Olin College
\end{abstract}

\begin{abstract}
Against a backdrop of compelling societal needs, graduates in science and engineering now must master their disciplines and demonstrate a sophisticated level of cognitive, affective and social development. This has lead a number of national and international commissions on science and engineering to urge educators to re-think the way in which STEM disciplines are taught. We have chosen to "repackage" a traditional undergraduate materials engineering curriculum in a form designed to promote the development of higher-order cognitive skills like self-directed learning and design. Classic metallurgy experiments have been converted to project-based learning experiences where students are put in the role of "designers" of problem solutions and faculty play the role of coaches. These include: designing, prototyping and marketing of a cast metal object; systems designing, building and testing of a fiber optic spectrometer; product improvement of a prosthetic device; evaluation of oxidation process for production; design and evaluation of a heat treatment process for roller bearings; and materials characterization of an everyday product. Projects were designed to leverage known relationships within the educational psychology literature that enable deeper learning. Evaluation of 36 juniors in a project-based learning course (i.e., the test cohort) against a quasi-control group in traditional engineering courses showed that the test cohort scored significantly higher on two motivation scales shown to be critical components in self-directed learning $(\mathrm{p}<0.001)$. The test cohort also reported a significantly higher use of peers as learning resources than the quasicontrol group. Their motivation scores also correlate highly with self-reported comfort with several aspects of design, implying that their motivation contributes significantly to students' ability to effectively engage in the design process. In this paper, we present examples of the materials engineering projects that were designed and implemented, and the design features that enable them to promote the development of sophisticated cognitive functioning.
\end{abstract}

\section{INTRODUCTION}

The case for transformational change in engineering education has been well articulated $[1,2]$, claiming that current curricular approaches do not develop the critical skill sets required of the $21^{\text {st }}$ century engineer[3, 4]. The competencies for our global marketplace include cultural sensitivity and agility in rapidly assimilating new information, along with teamwork, moral, ethical, and social development as well as life long learning and systems thinking skills[5]. In many ways, these competencies are already part of the US engineering program accreditation criteria developed in the 1990s that call for "the broad education necessary to understand the 
impact of engineering solutions in a global and societal context," "a recognition of the need for, and an ability to engage in life-long learning," "an ability to design a system, component, or process to meet desired needs" and "an ability to function on multi-disciplinary teams", "understanding professional and ethical responsibilities" [6]. However, traditional curricula focus on scientific and technological content. Engineering skills are viewed as being developed through the combination of these scientific and classroom laboratory experiences. Faced with the need to enable students to develop sophisticated cognitive skills (e.g., the ability to engage in life-long learning, systems thinking) or social skills (e.g., teamwork, cultural sensitivity), we need to rethink the way in which we "convert" students to graduates.

Conventional curriculum can be represented as a system in which students exit as graduates after a four-plus year dwell time. Faculty presume that the educational content enables the transformation to the science and engineering professional. We know from educational psychology, however, that learning cannot be separated from the social setting in which it occurs[7]. Just as a material's performance in a particular application results from the interplay between its properties, processing and structure, the graduate's performance results from the interplay between the curricular content, how that student processes the content, and the structure of the learning environment in which the content is learned. This concept is represented as a learning tetrahedron in the diagram below.

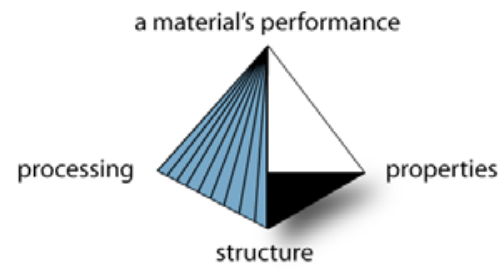

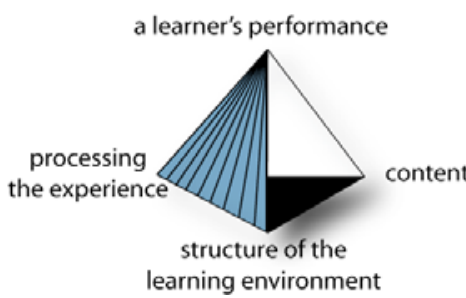

Figure 1. Learning tetrahedron analog. A material's performance in an application results from the interplay between its properties, processing and structure; in the same way, the graduate's performance

results from the interplay between the curricular content, how that student processes the content, and the structure of the learning environment in which the content is learned.

In order to target the development of competencies required for the $21^{\text {st }}$ century engineer, we created a model of student development that enables us to leverage the natural relationships that exist between the corners of the learning tetrahedron [8]. The model (the Four-Domain Development Diagram) was derived by synthesizing and number of empirical relationships from the educational psychology literature and its theoretical underpinnings are described elsewhere[8]. The model makes clear that the key elements required in the learning environment are: active learning experiences; experiences that promote strong working relationships with peers and faculty; assignments which require students to reflect on their mental models, discuss and resolve opposing viewpoints; experiences that elucidate the connection between the decisions we make as scientists and engineers and the impact on society. To test the effectiveness of the model as a design tool to enhance students' development of high-order learning skills, we compared the performance of test groups to those of quasi-control groups. The experimental settings and students' performance are described in the following sections.

\section{EXPERIMENTAL LEARNING ENVIRONMENTS}

Sophomore and junior-level materials engineering students worked in formal teams (assigned at the beginning of the term) on projects. These groups of students were considered the "test cohorts." The test cohorts had courses or parts of courses (generically, "learning experiences") 
that were designed according to the principles in the Four-Domain Development Diagram referenced in the previous section. Quasi-control cohorts or groups consisted of students from other engineering majors at the same university as the test group (California Polytechnic State University). Quasi-control groups received no intervention, but were tested at comparable points in their education. Presumably, the quasi-control groups experienced a more conventional engineering education. However, because engineering students are required to take the same 80$90 \%$ of their courses up through their sophomore year, the test and quasi-control groups of students are likely to have had very similar courses. The scope and magnitude of the projects represented a range of challenges and the materials science content was somewhat driven by the needs of the projects. For example, one project was oriented toward qualifying an oxidation furnace for production. This particular project was a fairly well-contained and narrow in its scope of learning objectives. However, another project involved a design improvement for a prosthetic device. This project spanned the course of a 10 -week quarter and required students to complete a biocompatibility analysis, design of experiments, statistical analysis, performance of a mechanical test and mechanics analysis.

\section{Surface modification as a project}

One of the projects involved converting a traditional heat treatment experiment into a project to design a particular case depth for roller bearings. Each team was given 10 untreated steel rollers and asked to produce between 3-6 rollers. The project goal to produce a set of rollers for typical Timken bearing prevented the teams from destructively testing the finished rollers. Each team was required justify that their bearings were actually within the design specification. This required destructively testing 4-7 rollers in the same batch and completing a statistical analysis that would enable them to infer that the case depth was within the design specification. Each team was given a graphical depiction of the overall project. This depiction, available directly from Blair London (blondon@calpoly.edu). This organizational scheme was developed to enable deeper learning[9] and reach visual learners., but is not displayed here due to space limitations.

\section{Materials analysis as a project}

In order to teach materials science associated with structural materials and biomaterials, students were given a project to improve upon the design of a prosthetic device. This assignment was fairly open-ended but required student to conduct some form of test to demonstrate that they improved upon the current design. About half of the learning occurred through self-directed research, while the remaining came in the form of faculty-directed readings and lectures. One group chose to improve upon the design of a total hip replacement. Their particular design involved a ceramic prosthetic femoral head that had a tendency for brittle fracture. Their design improvement consisted of re-designing the stem so that it absorbed shock loading rather than the ceramic prosthetic femoral head. This group of four students created a Solidworks@ part which was then used to do finite element analysis to determine the load distributions. The group also devised a mechanical test utilizing an accelerometer and an oscilloscope to simulate the dynamic response of the flexor neck.

This project enabled students to learn materials science and engineering competencies such as materials selection for biocompatibility, design of experiments, statistical analysis, and mechanical testing. However, the value of the project is in promoting students' engagement in 
the learning process (note that students were allowed to choose what type of prosthetic device they wanted to improve and choose how they wanted to improve it).

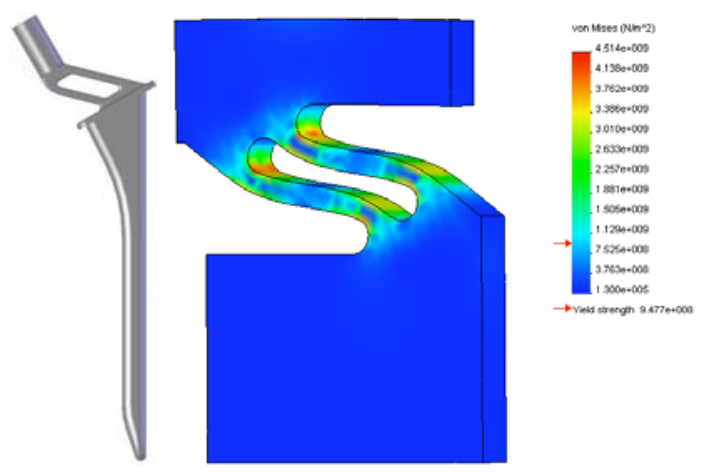

Figure 4. A group's redesign of the femur stem for a total hip replacement prosthetic device (left) and the finite element analysis of the flexor next (right).

\section{ASSESSMENT METHOD and ANALYSIS}

The test and quasi-control cohorts completed a number of assessment instruments, including the Situational Intrinsic Motivation Scale (SIMS) by Guay and Vallerand [10], and the design questionnaire (DQ) developed by Safoutin et al. [11]. Because the SIMS has been shown to be both internal reliability externally valid, confirmatory factor analysis was used on its four scales: intrinsic motivation (IM), identified regulation, external regulation and amotivation. The performance of the test cohorts (described in detail elsewhere [8]) indicated that the test cohort scored significantly higher on the two motivation scales (intrinsic motivation, identified regulation) shown to be critical components in self-directed learning (e.g., for IM, $d=0.83$, $p=0.001$ ), where $d=\frac{\left|\mu_{1}-\mu_{2}\right|}{\sigma}$, where $\mu_{i}$ is the mean of the $i$ population and $\sigma$ is the standard deviation of the populations, and $p$ indicates that $p$-value for the t-test. Exploratory factor analysis was used on the DQ results to identify factors and resulted in three factors: Identifying design solutions, Team management, Project management. The Chronbach's alpha for each of these was $0.927,0.897$ and 0.858 , respectively, indicating strong internal consistency (the maximum is 1.0 ).

Dichotomous groups were formed by a median split on the test groups' scores on the IM scales. The average score of DQ factors were computed for the "low" and "high" IM groups. These means were then used for a t-test, in an attempt to discern significant differences between the scores of the "high" and "low" IM groups. The following observations can be made:

- High IM students also report higher extrinsic motivation ( $\mathrm{d}=0.99, \mathrm{p}=0.008)$.

- High IM students are more confident about their ability to identify design solutions $(\mathrm{d}=1.19, \mathrm{p}=0.003)$.

- High IM students reported feeling no more confident about team management $(\mathrm{p}=0.11)$ or project management $(\mathrm{p}=0.14)$ than their low IM counterparts. However, both groups (high and low IM) have significantly higher IM scores than the quasi-control cohorts as noted before.

These results show that this particular cohort of students (36) were both intrinsically and extrinsically (e.g., motivated by external rewards, such as good grades) motivated. The result around the Team management and Project management are somewhat unsurprising in that both Team and Project management are heavily reliant upon social and affective skills that were not emphasized in the courses. This year, we have incorporated more intentional development of the underlying teamwork and project management skills. We note that the test cohort also reported a significantly higher use of peers as learning resources and the ability to relate collaboratively with peers than the quasi-control group. The implication is that intrinsic motivation is a key 
ingredient in learning and learners with higher degrees of intrinsic motivation are likely to have better performance in design teams.

\section{DISCUSSION}

While the projects presented above are wide ranging in terms of their depth, they are examples of how a standard materials science and engineering "experiment" can be reenvisioned as a design project, without losing core materials science principles. Each of them contains features that are designed into the learning experience for the purpose of enhancing the learning. For example, they all have formal teams for the purpose of promoting strong, positive working relationships with their peers. We note that these positive working relationships cannot be assumed to develop solely because students are forced into teams. The teamwork must be cultivated through structured exercises and working toward common goals. Each of the teams agrees to a common set of values and expectations at the beginning of the quarter through a team contract that is developed by the team (not by the instructor-this is very important, as creating the document by themselves promotes greater buy-in by the team members). While it is true that some of the students never revisit this document in the course of the quarter, the very act of getting it on the table enables the team to better function through greater awareness of each others' values and expectations.

Another trait embedded in the projects is the requirement for active modes of learning and specifically collaborative learning with their peers. These methods have been shown to be more effective at engaging students in the learning process, enabling deeper learning [12] and promoting self-directed learning [13]. The projects also involve real-world applications. That is, they show the materials science and engineering in the context in which it occurs. The intent here is to promote student engagement in the learning process by using concrete and tangible examples. This contrasts to a theoretical, abstracted learning situation where a student might be asked to envision a binary alloy made of hypothetical elements "A" and "B" ... and so on.

The design of the learning experiences also attempt to make use of Self-determination Theory [14], in which it is posited that learners are innately oriented toward learning and that providing opportunities for autonomy (i.e., the freedom to make choices) in the learning process promotes the learner's interest and motivation.

One of the difficulties of this approach is that the boundaries between the "right" amount of any quantity (e.g., "teamwork") and "too much" is not clear and probably varies for each learner. Additionally, to accomplish the projects, we have had to focus on the development of students' learning processes rather than on "covering" content in courses. At this point, the longterm effects of this shift in developmental focus is unknown.

\section{CONCLUSIONS}

In order to better prepare materials engineering graduates for the rapid pace of the global economy and its complex social challenges, we turned to known empirical relationships elucidated in the educational psychology literature and created a model which can be used to design learning experiences. The examples presented in this paper are re-cast versions of traditional materials science and engineering laboratory experiments. The new, design-oriented versions make use of the natural relationships within the learner to promote the development of qualities, such as intrinsic motivation that promote more engaged and deeper learning. This type of transformation can be done with learning experiences that are small or large in scope. The results are promising, showing measurable gains in skills for life-long learning as well as design. 


\section{ACKNOWLEDGMENTS}

The authors would like to gratefully acknowledge the students who entrusted their development to us. This work is supported in part by a grant from the National Science Foundation (Grant\#EEC-0530760). The viewpoints expressed are those of the authors and do not necessarily reflect those of the National Science Foundation.

\section{REFERENCES}

[1] G. Clough, Educating the Engineer of 2020: Adapting Engineering Education to the New Century. Washington, DC: National Academy of Engineering, 2005.

[2] "Educating Engineers for the 21st Century: The Industry View." vol. 2007: The Royal Academy of Engineering, 2006.

[3] J. Bransford, "Preparing People for Rapidly Changing Environments," Journal of Engineering Education, vol. 96, pp. 1-3, 2007.

[4] The Engineering of 2020: Visions of Engineering in the New Century. Washington DC: National Academy Press (U.S.), 2004.

[5] "Engineering Workforce Issues and Engineering Education: What are the Linkages?," in National Science Board-Sponsored Workshop Washington, D.C.: National Science Foundation, October 20, 2005.

[6] "Criteria for Accrediting Engineering Programs," ABET, Incorporated, 2007-2008.

[7] K. Bruffee, Collaborative Learning: Higher Education, Interdependence, and the Authority of Knowledge. Baltimore, MD: Johns Hopkins University Press, 1993.

[8] L. Vanasupa, J. Stolk, T. Harding, and R. Savage, "A Systemic Model of Development: Strategically Enhancing Students' Cognitive, Psychomotor, Affective and Social Development," in First International Conference on Research in Engineering Education, Honolulu, Hawaii, 2007.

[9] J. Bransford, National Research Council (U.S.). Committee on Developments in the Science of Learning, and National Research Council (U.S.). Committee on Learning Research and Educational Practice, How people learn : brain, mind, experience, and school, Expanded ed. Washington, D.C.: National Academy Press, 2000.

[10] F. Guay, R. J. Vallerand, and C. Blanchard, "On the Assessment of Situational Intrinsic and Extrinsic Motivation: The Situational Intrinsic Motivation Scale (SIMS)," Motivation and Emotion, vol. 24, pp. 175-213, 2000.

[11] M. J. Safoutin, C. J. Atman, R. Adams, T. Rutar, J. C. Kramlich, and J. L. Ridley, "A Design Attribute Framework for Course Planning and Learning Assessment," IEEE Transactions on Education, vol. 43, pp. 188-199, 2000.

[12] M. J. Prince and R. M. Felder, "Inductive Teaching and Learning Methods: Definitions Comparisons, and Research Bases," Journal of Engineering Education, vol. 95, pp. 1-16, 2006.

[13] S. Juisto and D. DiBiasio, "Experiential Learning Environments: Do They Prepare Our Students to be Self-Directed, Life-Long Learners?," Journal of Engineering Education, vol. 95, pp. 195-204, 2006.

[14] R. M. Ryan and D. M. Deci, "Self-determination Theory and the Facilitation of Intrinsic Motivation, Social Development, and Well-being," American Psychologist, vol. 55, pp. 68-78, 2000. 